in vivo $34: 3205-3215(2020)$

doi:10.21873/invivo.12156

\title{
Continuity of Tumor Microenvironmental Suppression in AOM/DSS Mice by Fucoxanthin May Be Able to Track With Salivary Glycine
}

\author{
MASARU TERASAKI ${ }^{1,2}$, RYOTA KIMURA ${ }^{1}$, ATSUHITO KUBOTA ${ }^{1}$, HIROYUKI KOJIMA ${ }^{1}$, \\ TAKUJI TANAKA ${ }^{3}$, HAYATO MAEDA ${ }^{4}$, KAZUO MIYASHITA $^{5}$ and MICHIHIRO MUTOH ${ }^{6}$ \\ ${ }^{1}$ School of Pharmaceutical Sciences, and ${ }^{2}$ Advanced Research Promotion Center, \\ Health Sciences University of Hokkaido, Hokkaido, Japan; \\ ${ }^{3}$ Department of Diagnostic Pathology and Research Center of Diagnostic Pathology, \\ Gifu Municipal Hospital, Gifu, Japan; \\ ${ }^{4}$ Faculty of Agriculture and Life Science, Hirosaki University, Aomori, Japan; \\ ${ }^{5}$ Laboratory of Biofunctional Material Chemistry, Division of Marine Bioscience, \\ Graduate School of Fisheries Sciences, Hokkaido, Japan; \\ ${ }^{6}$ Epidemiology and Preventions Group, Center for Public Health Sciences, National Cancer Center, Tokyo, Japan
}

\begin{abstract}
Background/Aim: Fucoxanthin (Fx) is a potent anticancer carotenoid, demonstrated by mouse cancer models. We recently showed the decrease of salivary glycine could represent an attenuation of tumor microenvironment (TME) formation in an azoxymethane/dextran sodium sulfate (AOM/DSS) colon cancer mouse model. However, it remains unclear whether the salivary glycine is an indicator for continuous TME suppression of Fx in the mice. Materials and Methods: In the present study, we time-dependently analyzed salivary metabolites in AOM/DSS mice, and investigated candidate markers to evaluate the continuous inhibition of colonic TME formation and carcinogenesis in the mice with and without Fx. Results: Fx attenuated the incidence and/or multiplicity of colonic lesions developed in AOM/DSS mice. The number of apoptosis-like cleaved caspase-3 $3^{\text {high }}$ cells was significantly increased, and colonic cancer stem cell-like CD44high/EpCAM high cells and cancerassociated fibroblast-like $\alpha S M A^{\text {high }}$ cells were significantly decreased in colon mucosal tissue by Fx administration.
\end{abstract}

This article is freely accessible online.

Correspondence to: Masaru Terasaki, School of Pharmaceutical Sciences and Cancer Prevention Laboratories, Health Sciences University of Hokkaido, 1757 Kanazawa, Ishikari-Tobetsu, Hokkaido 061-0293, Japan. Tel: +81 133231211 ext. 3156, Fax +81 133231669, e-mail: terasaki@hoku-iryo-u.ac.jp

Key Words: Fucoxanthin, glycine, cancer chemoprevention, saliva, tumor microenvironment.
Salivary glycine at 4, 11 and 14 weeks after the final DSS exposure in the Fx-treated mice showed successful and consecutive decreases of 0.5-, 0.4- and 0.7-fold respectively compared to that of control mice. Conclusion: Salivary glycine is a valuable indicator that could evaluate sustained efficacy of cancer chemopreventive effects of $F x$ in AOM/DSS mice.

Some biological materials from cancer patients, such as blood, saliva, urine, and tissue itself, show different characteristics compared to those from healthy controls. Among those samples containing low molecular weight substances, saliva is a valuable biomarker because of easy and non-invasive access. It has been reported that many salivary metabolites, such as alanine, glutamic acid, glycine, leucine, phenylalanine, proline, valine, taurine, pipecolic acid, ornithine and lactic acid, are significantly altered in patients with oral, breast, pancreatic and gastric cancers compared to those in healthy controls (1-5).

Similarly, the metabolite changes have been clarified on biological samples in cancer-burdened and unburdened animals. For instance, metabolites in serum and intestinal polyp in colorectal cancer model $A p c^{\mathrm{Min} /+}$ mice could be distinguished with the serum and normal intestinal tissue in wild-type mice, respectively (6). In addition, some metabolite alterations were observed in plasma. Glutamic acid, glycine, methionine, phenylalanine, threonine and tryptophan were significantly correlated with promotion of tumorigenesis in $A p c^{\mathrm{Min} /+}$ mice with a high-fat diet (7). Treatment with acyclic retinoid, a promising cancer preventive agent, in hepatic cancer model mice showed 
metabolic reprogramming in liver tissue (8). However, it remains unclear whether salivary metabolites represent a continuous effect of cancer chemoprevention in both humans and rodents.

Fucoxanthin (Fx) (Figure 1), a marine allenic compound, is abundantly contained in edible brown algae, such as Undaria pinnatifida (wakame) and Sargassum horneri (akamoku) $(9,10)$. Fx has the potential to inhibit carcinogenesis, inflammation, obesity and diabetes in humans and rodents (11-15). Fx is transformed in intestinal tissue to deacetylated fucoxanthinol $(\mathrm{FxOH})$, which is the primary metabolite detected in blood and various tissues (1618). To date, no evidence has been provided that Fx or FxOH exerts cancer preventive effects on healthy people or therapeutic effects on cancer patients.

Recently, we demonstrated that Fx administration $[30 \mathrm{mg} / \mathrm{kg}$ body weight (bw) for 8 weeks (wks) after the final dextran sodium sulfate (DSS) exposure] significantly suppressed development of the tumor microenvironment (TME) and colonic lesions in an azoxymethane (AOM)/DSS-induced colon cancer mouse model. In addition, the amount of salivary glycine was significantly decreased 0.5 -fold compared to that of control mice by Fx treatment (19). However, in this experiment, the salivary metabolite in the Fx-treated mice was evaluated just once after sacrifice. Thus, it remains unclear whether the change of salivary metabolite shows continuous predictive potential as a marker for cancer chemoprevention.

In the present study, we showed that salivary metabolites could be continuous indicators for suppression of TME in AOM/DSS model mice by Fx administration for 14 wks after the final DSS exposure.

\section{Materials and Methods}

Chemicals. Fx-oil (5.0 w/v\%) comprising palm oil, minor ingredients, and moisture was donated by Oryza Oil \& Fat Chemical Co. Ltd. (Aichi, Japan). Palm oil alone was arranged as a control oil. Azoxymethane (AOM), a genotoxic carcinogen, and isoflurane were purchased from Wako Pure Chemicals (Osaka, Japan). Dextran sodium sulfate (DSS), a tumor promoter, was from MP Biomedicals (Solon, OH, USA). Pilocarpine hydrochloride was from SigmaAldrich (St. Louis, MO, USA). CD44 conjugated with Alexa Fluor 488 and EpCAM conjugated with APC antibodies were purchased from Biolegend (San Diego, CA, USA) and eBioscience (San Diego, CA, USA), respectively. $\alpha$-Smooth muscle actin ( $\alpha$ SMA) and cleaved caspase-3 (Asp175) conjugated with Alexa Fluor 488 antibodies were purchased from Cell Signaling Technology (Danvers, MA, USA). Goat anti-rabbit IgG conjugated with Alexa Fluor 488 and 546, and ProLong Gold Antifade conjugated with 4',6-diamidino-2-phenylindole (DAPI) were obtained from Invitrogen (Carlsbad, CA, USA). All other chemicals and solvents were from commercial sources.

Animal experiments. Male ICR mice (5 wks of age, Sankyo Labo Service, Shizuoka, Japan) were randomly housed into four groups

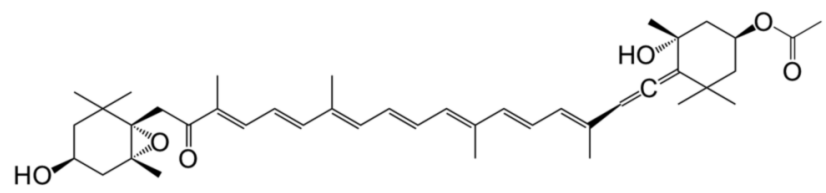

Figure 1. Molecular structure of fucoxanthin (Fx). $\mathrm{C}_{42} \mathrm{H}_{58} \mathrm{O}_{6}$. M.W. 658.91 .

(5 mice/cage, 10 mice per group) and were maintained in a $12-\mathrm{h}$ light-dark cycle room with controlled humidity and temperature. The mice were given solid food and water ad libitum until sacrifice (about 16 wks later). After a week of acclimation, mice in groups 1 and 2 received a single IP injection of AOM $(10 \mathrm{mg} / \mathrm{kg}$ of bw). Groups 3 and 4 received an IP injection of saline. One week later, mice in groups 1 and 2 were given $1.5 \mathrm{w} / \mathrm{v} \%$ DSS continuously in drinking water for 1 week. Mice in groups 3 and 4 were allowed normal water only through that period. Mice in groups 1 and 3 were orally administrated Fx-oil at $30 \mathrm{mg} / \mathrm{kg}$ bw using a gastric sonde needle on 3 times per week during the final 14 weeks. Mice in groups 2 and 4 were given the equivalent volume of palm oil. In the timing of 3,6,13 and 16 wks that implied $0,4,11,14$ wks after the final DSS exposure, mice were anesthetized by using $2.0 \%$ isoflurane (air, $2.0 \mathrm{l} / \mathrm{min}$ ), pilocarpine injected $(5 \mathrm{mg} / \mathrm{kg}, \mathrm{SC}$ ), and then saliva $(<500 \mu \mathrm{l})$ collected for $20 \mathrm{~min}$ (scheme in Figure $2 \mathrm{~A}$ ). Mice were sacrificed under isoflurane inhalation at 16 wks. Subsequently, the large intestine of each mouse was excised, cut open longitudinally and fixed in $10 \%$ formalin/PBS for at least 48 h. Hematoxylin-eosin stained and unstained sections were prepared by Morphotechnology (Sapporo, Japan). Histopathologic features were analyzed in colorectal mucosa in mice. The experimental project was approved by the Institutional Review Board for Animal Experimentation in the Health Sciences University of Hokkaido, performed under the Guidelines for Animal Care and Use in the Health Sciences University of Hokkaido (identification code, 028b; authorization, Mar 7, 2018).

Fluorescence immunohistochemistry. Formalin-fixed paraffin embedded tissue sections were dewaxed using xylene. For the antigen recovery, the sections were treated with $1 \mathrm{mM}$ EDTA buffer ( $\mathrm{pH} 9.0)$ at $95^{\circ} \mathrm{C}$ for $20 \mathrm{~min}$. Subsequently, the sections were washed with trisbuffer saline containing $0.1 \%$ polyoxyethylene (20) sorbitan monolaurate (TBST) and were blocked with $5 \mathrm{w} / \mathrm{v} \%$ BSA-TBST at room temperature for $1 \mathrm{~h}$. To evaluate protein expression level of cancer-associated fibroblast (CAF)-like $\alpha$ SMA, sections were incubated with anti- $\alpha$ SMA antibody (1:50 dilution in 5\%BSA/TBST) overnight at $4^{\circ} \mathrm{C}$ and then incubated with a goat anti-rabbit $\operatorname{IgG}$ conjugated with Alexa Fluor 488 (1:100 dilution in 5\%BSA/TBST) for $1 \mathrm{~h}$ at room temperature. To detect apoptosis-like cells, sections were incubated with anti-cleaved caspase- 3 antibody conjugated with Alexa Fluor 488 (1:50 dilution in 5\%BSA/TBST) overnight at $4^{\circ} \mathrm{C}$. To detect colonic cancer stem cell (CCSC)-like cells, sections were incubated with an anti-CD44 antibody conjugated with Alexa Fluor 488 and an anti-EpCAM antibody conjugated with an APC antibody (1:50 dilution in 5\%BSA/TBST) overnight at $4^{\circ} \mathrm{C}$. All sections were rinsed with TBST and PBS and were mounted using ProLong Gold Antifade reagent with DAPI. Immunofluorescence images were captured on a Nikon TE2000 confocal microscope with EZ-C1 

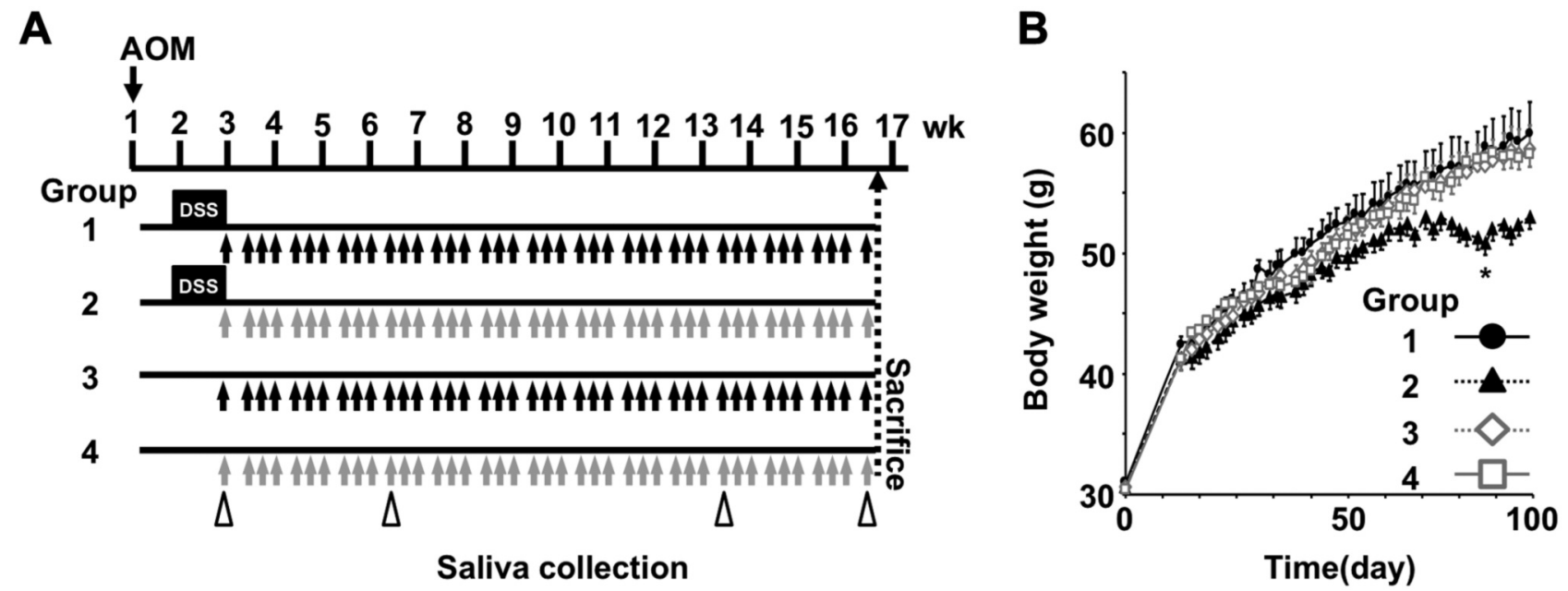

Figure 2. Body weight changes in AOM/DSS-treated mice. (A) Administration protocol. The mice in groups 1 and 3 were administered Fx-oil at 30 mg Fx/kg body weight (bw) 3 times per week for 14 weeks (black arrows). The mice in groups 2 and 4 control groups were given the equivalent volume of control-oil (gray arrows). The mice in groups 1 and 2 were treated with AOM/DSS. Saliva in mice was collected under isoflurane anesthesia after pilocarpine injection (white arrow heads). (B) Body weight changes from the day just before AOM administration to the sacrifice day. Means \pm SE $(n=9-10)$. A significant difference was found between groups 1 and 2 (97 days after AOM injection): *p<0.05 by one-way ANOVA with post-hoc Tukey-Kramer test.

acquisition software (Nikon, Melville, NY, USA). The number of cleaved caspase- $3^{\text {high }}, \mathrm{CD} 44^{\text {high/EpCAM }}{ }^{\text {high }}$ and $\alpha \mathrm{SMA}^{\text {high }}$ cells in colonic adenocarcinoma and mucosal crypts were evaluated per set tissue area $\left(\mathrm{mm}^{2}\right)$.

Gas chromatography-mass spectrometry (GC-MS). N-methyl$N$ (trimethylsilyl)-trifluoroacetate (MSTFA), methoxyamine hydrochloride and 2-isopropylmalic acid (2-IPMA) were purchased from GL Sciences (Tokyo, Japan), MP Biomedicals (Solon, OH) and Sigma-Aldrich (St. Louis, MO, USA), respectively. Saliva from each mouse $(100 \mathrm{ml})$ was divided into a microtube. An internal standard of 2-IPMA $(0.05 \mu \mathrm{g})$ was added to each saliva sample. The samples were mixed with $0.5 \mathrm{ml}$ of $\mathrm{CH}_{3} \mathrm{OH} / \mathrm{CHCl}_{3} / \mathrm{DW}$ (2.5:1:1, $\mathrm{v} / \mathrm{v} / \mathrm{v}$ ) and centrifuged at $16,000 \mathrm{~g}$ for $5 \mathrm{~min}$. The upper phase was washed with $0.5 \mathrm{ml}$ of DW once and oximated with $30 \mu \mathrm{l}$ of methoxyamine hydrochloride solution $(20 \mathrm{mg} / \mathrm{ml}$ in dry pyridine $)$ at $30^{\circ} \mathrm{C}$ for $90 \mathrm{~min}$ and then derivatized with $15 \mu \mathrm{l}$ of MSTFA at $37^{\circ} \mathrm{C}$ for $30 \mathrm{~min}$. Gas chromatography-mass spectrometry (GC-MS) analysis was performed on a GC-MS QP5000 (Shimadzu, Kyoto, Japan). The GC column was a $30 \mathrm{~m}$ x $0.25 \mathrm{~mm}$ (i.d.) Rxi-5ms fused silica column (film thickness: $0.25 \mu \mathrm{m}$, Restek, Bad Homburg, Germany). The column temperature program: $80^{\circ} \mathrm{C}$ for $2 \mathrm{~min}, 80$ $330^{\circ} \mathrm{C}(62.5 \mathrm{~min})$ at $4^{\circ} \mathrm{C} / \mathrm{min}$ and then $330^{\circ} \mathrm{C}$ for $8 \mathrm{~min}$ with $\mathrm{He}$ as a carrier using $15.7 \mathrm{kPa}(0.5 \mathrm{mlmin})$; injection volume, $0.5 \mu \mathrm{l}$ (splitratio mode, $33 \%$ ); interface temperature, $250^{\circ} \mathrm{C}$; source temperatures, $230^{\circ} \mathrm{C}$. Authentic standard spectra and GC-MS reference libraries were used to identify peaks of salivary metabolites in the mice. All metabolite contents were expressed as picomole (pmol) metabolite per $100 \mu \mathrm{l}$ of saliva.

Statistical analyses. All the results are expressed as mean $\pm \mathrm{SE}$ values. Significant differences from control groups in mice were determined by Fisher's exact test for tumor incidence and by Wilcoxon rank sum test for all others. Comparison among four groups was analyzed by one-way analysis of variance (ANOVA) with Tukey-Kramer post hoc tests. Differences were considered statistically significant at $* p<0.05$.

\section{Results}

Inhibition of colorectal lesions in AOM/DSS-treated mice by $F x$. Differences of clinical signs and food intake were not observed among the five groups for a total $16 \mathrm{wks}$, that is after AOM, DSS and Fx administrations. No significant differences in the body weight of mice among the five groups were observed during the Fx treatment period except for a limited time point between groups 1 and 2 (97 days after AOM injection; $* p<0.05$; Figure $2 \mathrm{~B}$ ). Pathological features indicated that the incidence and/or multiplicity of colon mucosal ulcer, dysplastic crypts, adenoma and adenocarcinoma tended to be lower in group 1 compared to those in control mice in group 2, and did not emerge in either group 3 or 4 (Figure 3 and Table I).

Changes of apoptosis-like cells in colon adenocarcinoma and mucosal crypts of AOM/DSS mice by Fx administration. The number of cells with high cleaved caspase- 3 proteins in colon adenocarcinoma and mucosal crypts were decided to be apoptosis-like caspase- $3^{\text {high }}$ cells. The number of cleaved caspase- $3^{\text {high }}$ cells in colon adenocarcinoma was significantly increased at 1.8 -fold by $\mathrm{Fx}$ administration in group 1 compared to those of group 2: group 1, 141.4 \pm 16.7 ; group 2, $78.3 \pm 9.1$ for the number of cleaved caspase- $3^{\text {high }}$ cells per tissue area $\left(\mathrm{mm}^{2}\right)$ (Figure 4A and B). The number of cleaved 


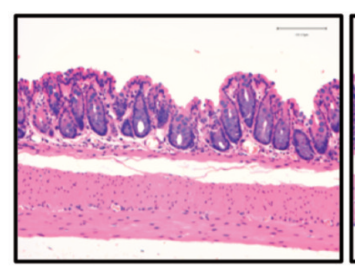

Normal mucosa

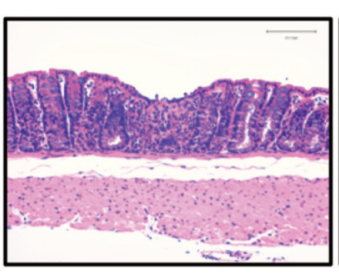

Mucosal ulcer

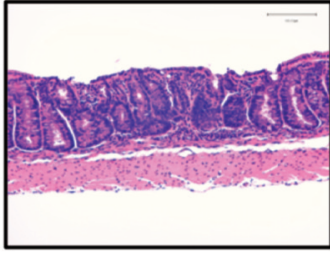

Dysplastic crypt (high grade)

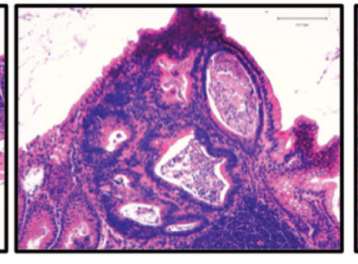

Adenoma

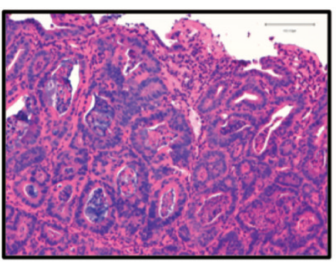

Adenocarcinoma

Figure 3. Representative histopathological evaluation of colonic lesions. Bars are $100 \mu \mathrm{m}$.

Table I. Incidence (\%) and multiplicity (no. of lesion/colon) of colonic lesions.

\begin{tabular}{|c|c|c|c|c|c|c|}
\hline Group no. & Treatment & Mucosal ulcer ${ }^{\mathrm{a}}$ & $\begin{array}{l}\text { Dysplastic crypts } \\
\text { (high grade) }\end{array}$ & Adenoma & Adenocarcinoma & Total tumors \\
\hline 1 & $\begin{array}{c}\text { AOM-DSS } \\
\text { Fx }^{\mathrm{c}} 30 \mathrm{mg} / \mathrm{kg} \text { bw }\end{array}$ & $20 \% 0.6 \pm 0.6^{\mathrm{d}}$ & $0 \%$ & $20 \% \quad 0.2 \pm 0.2$ & $40 \% \quad 0.6 \pm 0.4$ & $40 \% \quad 0.8 \pm 0.4$ \\
\hline 2 & AOM-DSS & $50 \% \quad 0.5 \pm 0.5$ & $50 \% 1.8 \pm 1.0$ & $50 \% \quad 0.8 \pm 0.5$ & $50 \% 1.8 \pm 1.0$ & $50 \% 2.5 \pm 1.4$ \\
\hline 3 & Fx $30 \mathrm{mg} / \mathrm{kg}$ bw & $0 \%$ & $0 \%$ & $0 \%$ & $0 \%$ & $0 \%$ \\
\hline 4 & None & $0 \%$ & $0 \%$ & $0 \%$ & $0 \%$ & $0 \%$ \\
\hline
\end{tabular}

aDetected as mostly healed. bAOM-DSS, Azoxymethane-dextran sulfate sodium. ${ }^{\mathrm{c} F x}$, Fucoxanthin. ${ }^{\mathrm{d} A l l}$ data of multiplicity are shown as mean \pm SE $(n=4-5)$. No data showed significance for Fisher's exact probability test, vs. AOM/DSS control mice (group 2).

caspase- $3^{\text {high }}$ cells in colon mucosal crypts was significantly increased by 1.8-, 2.1- and 2.0-fold by Fx administration in group 1 compared to those cells in groups 2, 3 and 4: group $1,65.1 \pm 6.1$; group 2, 35.4 \pm 4.4 ; group $3,31.7 \pm 4.0$; group 4, $33.1 \pm 5.5$ cells per tissue area $\left(\mathrm{mm}^{2}\right)$ (Figure $4 \mathrm{C}$ and $\left.\mathrm{D}\right)$.

Suppressive effect of Fx on CCSCs and CAFs in colon adenocarcinoma and mucosal crypts of AOM/DSS-treated mice. Cells with high CD44 and EpCAM proteins were determined to be CCSC-like CD44 ${ }^{\text {high }} / \mathrm{EpCAM}^{\text {high }}$ cells in colon adenocarcinoma and mucosal crypts. The number of $\mathrm{CD} 44^{\text {high }} / \mathrm{EpCAM}^{\text {high }}$ cells in colon adenocarcinoma was significantly decreased 0.7 -fold by $\mathrm{Fx}$ administration in group 1 compared to cells in group 2: group 1, 29.0 2.4 ; group 2, 43.9 \pm 3.0 (Figure $5 \mathrm{~A}$ and $\mathrm{B}$ ). The number of $\mathrm{CD} 44^{\text {high }} / \mathrm{EpCAM}^{\text {high }}$ cells in colon mucosal crypts was decreased 0.5 -fold by Fx administration in group 1 compared to those cells in group 2, and was similar to those cells in groups 3 and 4: group 1, 50.7 \pm 8.1 ; group 2, 101.3 \pm 8.1 ;

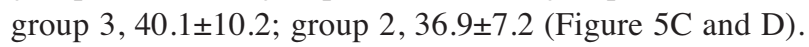

Cells with high stroma $\alpha$ SMA proteins were determined to be CAF-like $\alpha$ SMA ${ }^{\text {high }}$ cells in colon adenocarcinoma and mucosal crypts. No significant difference in the number of $\alpha_{S M A}{ }^{\text {high }}$ cells in colon adenocarcinoma was observed between groups 1 and 2 (Figure 6A and B). The number of $\alpha_{S M A}{ }^{\text {high }}$ cells in colonic mucosal crypts was decreased 0.6fold by Fx administration in group 1 compared to cells in group 2, and was similar to those cells in groups 3 and 4 : group $1,0.6 \pm 0.1$; group $2,1.0 \pm 0.1$; group $3,0.7 \pm 0.1$; group $4,0.8 \pm 0.1$ (Figure 6C and D).

Continual observation of salivary metabolites from AOM/DSStreated mice. Five of the salivary metabolites were detected by GC-MS in Fx-administrated AOM/DSS-treated mice through the entire experimental period (Figure 7). Glycine and succinic acid were significantly and constantly lower in group 1 than in group 2 during the experimental period from 4 to 14 wks: glycine in group $1,92.8 \pm 20.4$ (0 wk), 131.4 \pm 16.4 (4 wks), $139.4 \pm 38.0$ (11 wks), 195.0 \pm 11.3 (14 wks); glycine in group 2, $74.1 \pm 9.9$ ( $0 \mathrm{wk}$ ), $246.9 \pm 42.8$ (4 wks), $335.8 \pm 49.6$ (11 wks), $280.7 \pm 16.5$ (14 wks); succinic acid in group 1, 65.4 $\pm 13.6(0$ wk), $134.7 \pm 10.8$ (4 wks), $141.0 \pm 19.2$ (11 wks), $180.5 \pm 12.7$ (14 wks); succinic acid in group 2, 63.3 \pm 7.4 (0 wk), 294.4 \pm 46.3 (4 wks), $465.1 \pm 61.0$ (11 wks), $292.3 \pm 18.4$ (14 wks) pmol metabolite/100 $\mu \mathrm{l}$ saliva. No significant difference was constantly observed in other salivary metabolites, such as pelargonic, malic and aspartic acids, during the experimental period. Of note, no significant differences were observed in the five metabolites among the four groups at $0 \mathrm{wk}$ (Figure 7).

\section{Discussion}

We demonstrated that Fx administration suppressed the development of colonic lesions, CCSCs and CAFs, and 
A
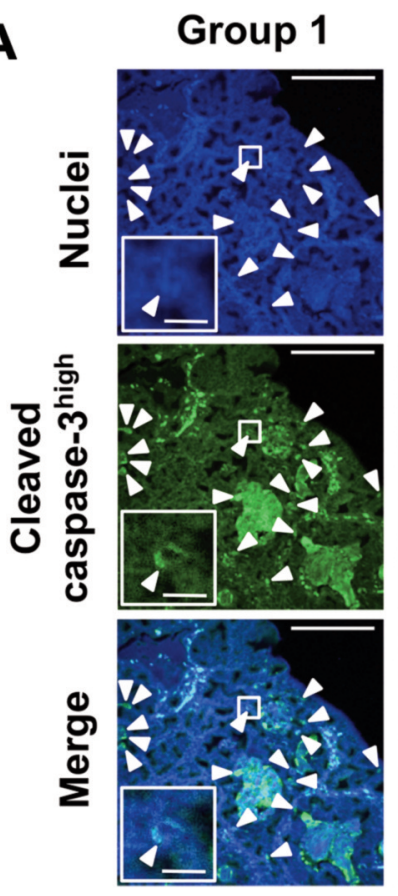

C

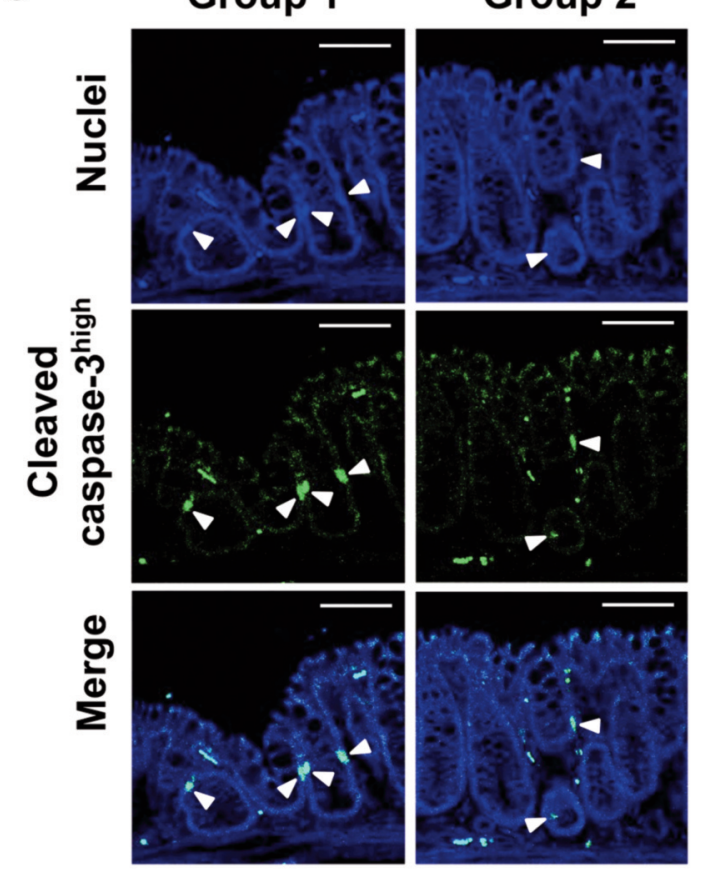

B

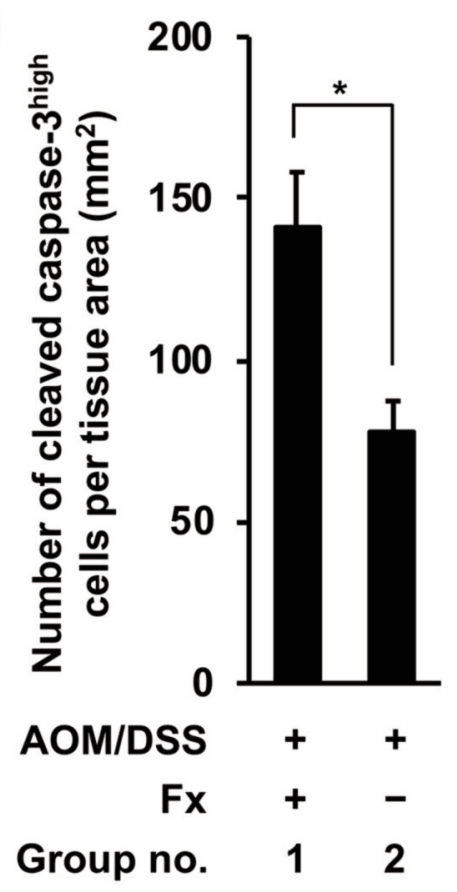

D

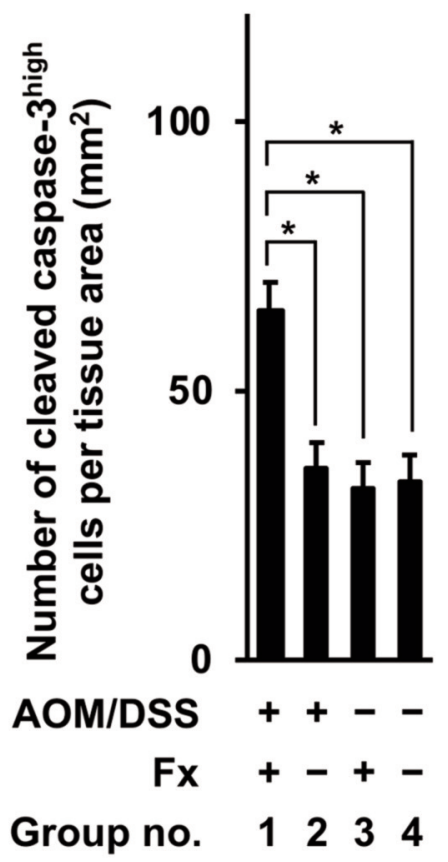

Figure 4. Immunohistochemical staining of apoptosis-like cleaved caspase-3high cells in colonic adenocarcinoma and mucosal crypts in AOM/DSS mice with or without fucoxanthin (Fx). The nuclei (blue fluorescence) and cleaved caspase-3 (green fluorescence) were observed by confocal microscopy. $(A, D)$ Representative confocal images of cleaved caspase- $3_{\text {high }}$ cells in colonic adenocarcinoma and mucosal crypts, respectively (white arrow heads). Long and short bars in colonic adenocarcinoma are 100 and $10 \mu \mathrm{m}$, respectively. Bars in colonic mucosal crypts are 50 um. (B, D) The number of cleaved caspase-3high cells per tissue area $\left(\mathrm{mm}^{2}\right)$ was estimated in the colonic adenocarcinoma and crypts, respectively. $(B)$ Means $\pm S E$ ( $n=3$ and 7 in group 1 and 2, respectively). ${ }^{*} p<0.05$ by Wilcoxon rank sum test. (D) Means $\pm S E$ ( $n=5$ ). No significance (n.s.) by oneway ANOVA with post-hoc Tukey-Kramer test. 
A

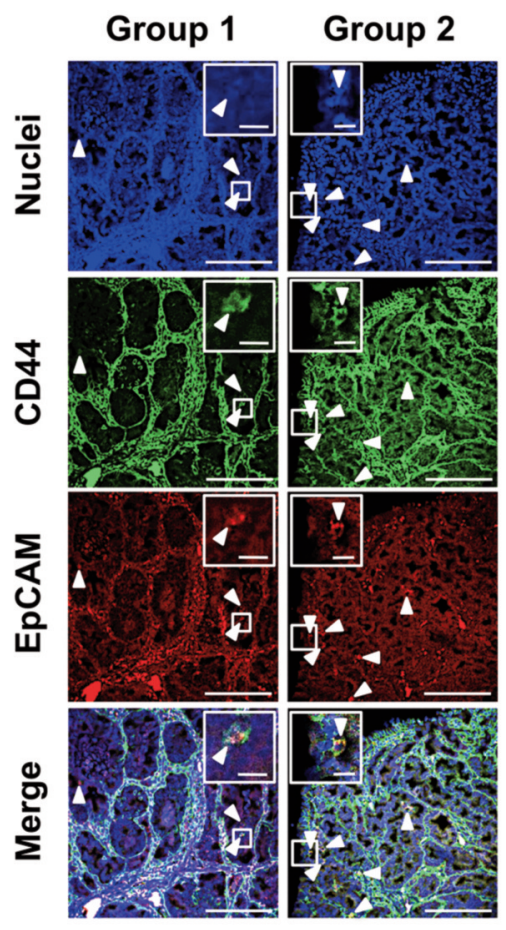

C
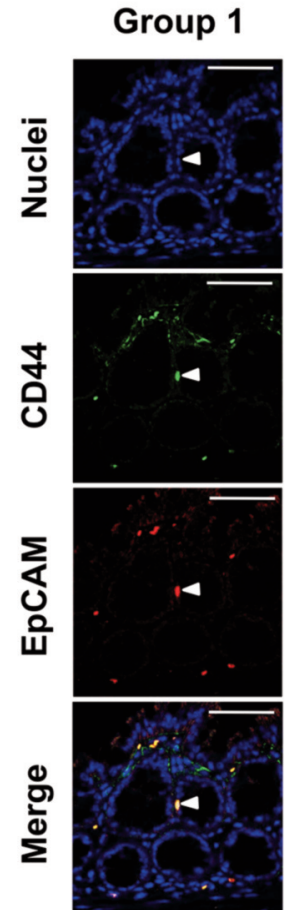

Group 2

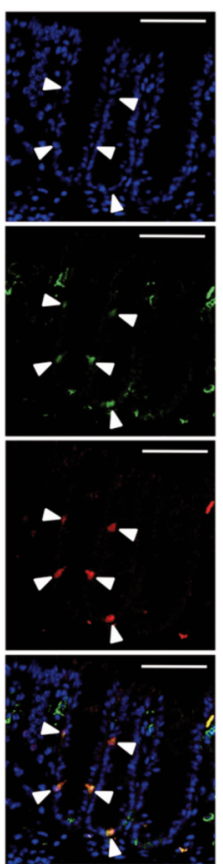

B

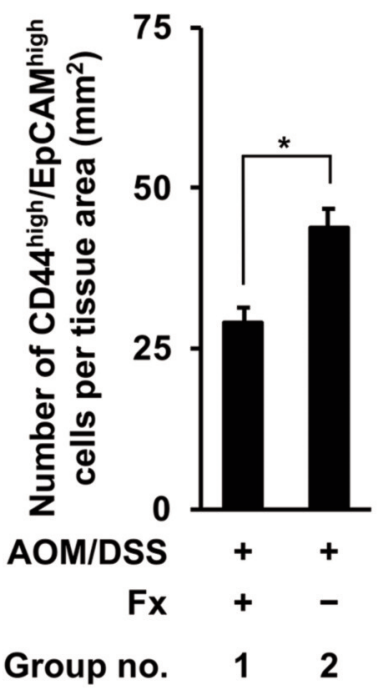

D

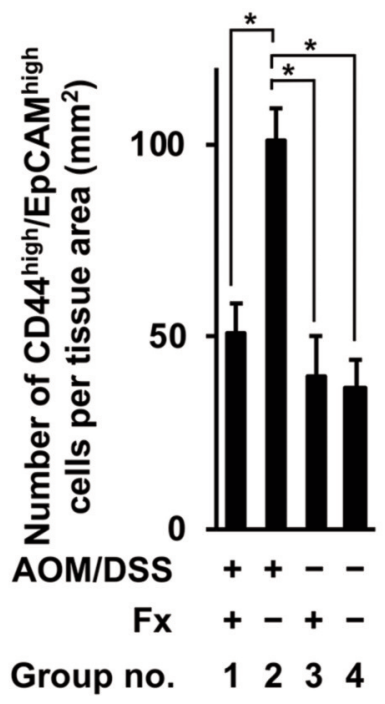

Figure 5. Immunohistochemical staining of colorectal cancer stem cells-like CD44high/EpCAMhigh cells in colonic adenocarcinoma and mucosal crypts in AOM/DSS mice with or without fucoxanthin ( $F x$ ). The nuclei (blue fluorescence), CD44 (green fluorescence), and EpCAM (red fluorescence) were observed by confocal microscopy. $(A, C)$ Representative confocal images of CD44high/EpCAM high cells in the colonic adenocarcinoma and mucosal crypts, respectively (white arrow heads). Long and short bars in colonic adenocarcinoma are 100 and 10 um, respectively. Bars in colonic mucosal crypts are $50 \mu \mathrm{m} .(B, D)$ The number of CD44high/EpCAM high cells per tissue area $\left(\mathrm{mm}^{2}\right)$ was estimated in the colonic adenocarcinoma and mucosal crypts, respectively. (B) Means $\pm S E$ ( $n=3$ and 7 in group 1 and 2 , respectively). ${ }^{*} p<0.05$ by the Wilcoxon rank sum test. (D) Means $\pm S E$ $(n=5) . * p<0.05$ by one-way ANOVA with post-hoc Tukey-Kramer test. 
A

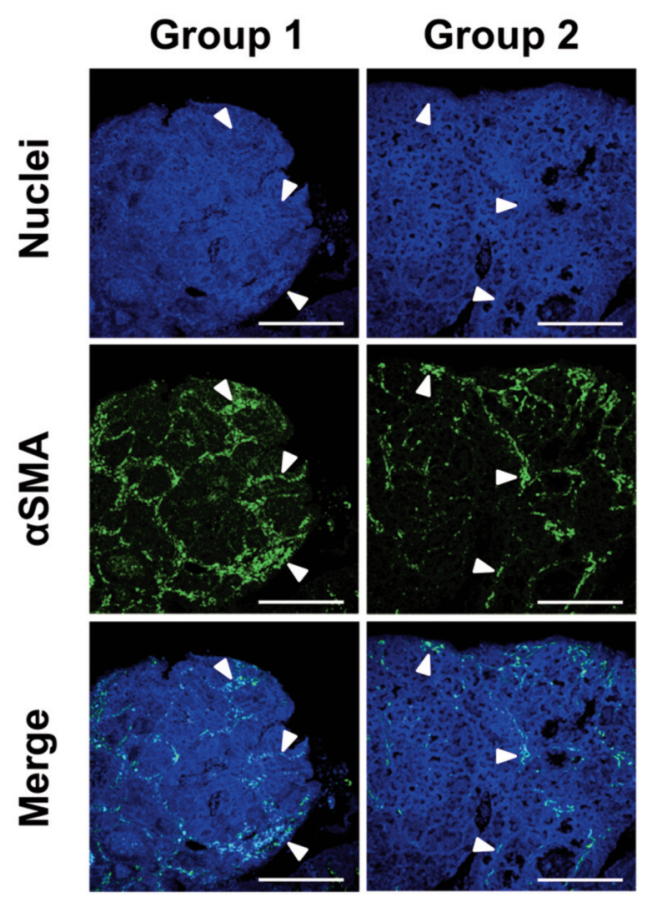

C

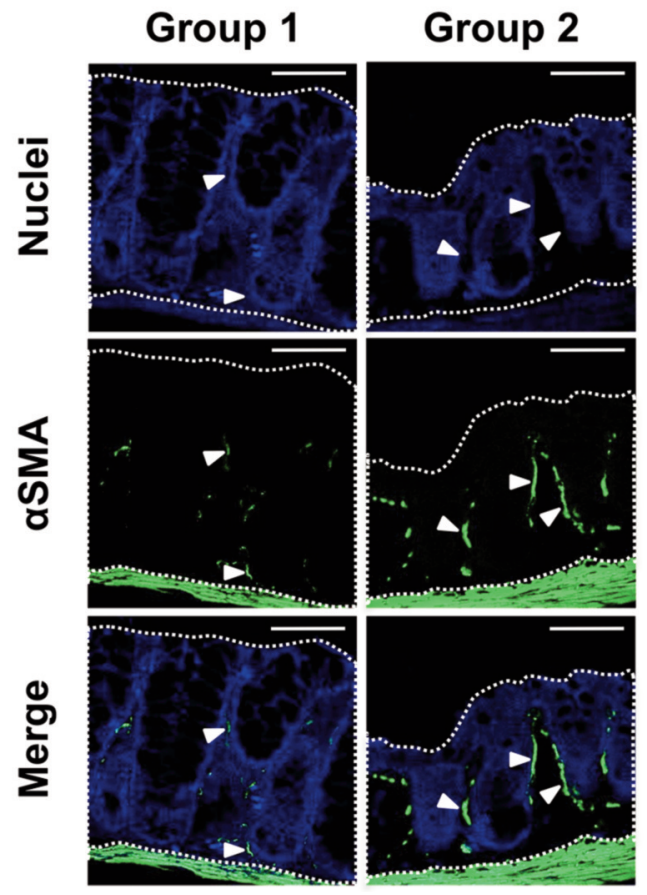

B

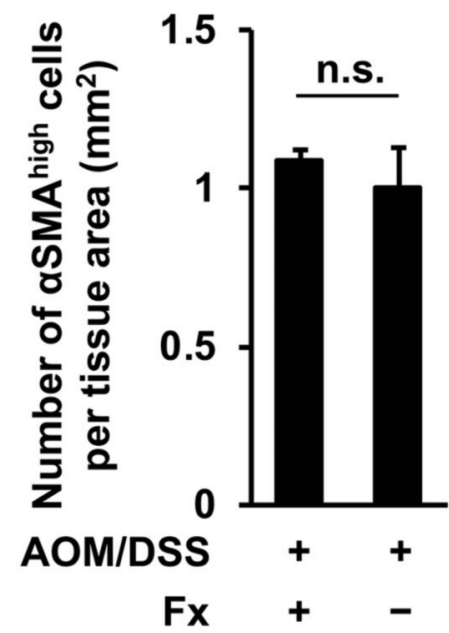

Group no. 12

Figure 6. Immunohistochemical staining of cancer-associated fibroblast-like $\alpha S M A^{\text {high }}$ cells in colonic adenocarcinoma and mucosal crypts in AOM/DSS mice with or without fucoxanthin ( $F x$ ). The nuclei (blue fluorescence) and $\alpha$ SMA (green fluorescence) were observed by confocal microscopy. $(A, C)$ Representative confocal images of aSMA high cells in the colonic adenocarcinoma and mucosal crypts, respectively. White

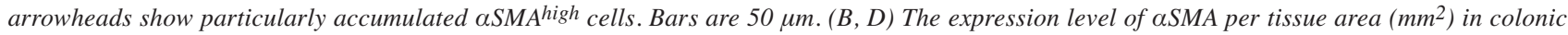
adenocarcinoma and mucosal crypts (dotted line enclosed area) was estimated as -fold by calculating the relative imaging density by normalizing to the value of the control mice (group 2), respectively. (B) Means $\pm S E$ ( $n=3$ and 7 in group 1 and 2, respectively). No significance (n.s.) by Wilcoxon rank sum test. (D) Means $\pm S E(n=5) .{ }^{*} p<0.05$ by one-way ANOVA with post-hoc Tukey-Kramer test. 
increased apoptosis-like cells in colon adenocarcinoma and/or mucosal tissue of AOM/DSS model mice. In addition, amounts of salivary glycine and succinic acid in Fx-treated AOM/DSS model mice were kept lower compared to those of control mice during the experimental period. This is the first report to suggest that salivary prognosticators continuously show the suppressive effect of TME in a carcinogenic mouse model by Fx.

Our previous study showed that Fx administration (3 times per week for 8 wks after the final DSS exposure) significantly suppressed accumulations of CCSCs, CAFs, tumor-associated macrophages and dendritic cells composed of TME in AOM/DSS mice (19). In this experiment, a salivary metabolite, glycine, was sampled just before the sacrifice time point. Thus, changes of salivary metabolites linked to cancer development were not assessed in mice. In the present study, we investigated metabolite profiles, apoptosis induction, TME development in colonic adenocarcinoma and mucosal crypts in a time-dependent manner in AOM/DSS-treated mice with Fx administration (3 times per week for $14 \mathrm{wks}$ after the final DSS exposure) to overcome this problem.

Fx attenuated the incidence and/or multiplicity of colon mucosal ulcers, dysplastic crypts (high grade), adenoma and adenocarcinoma in group 1 ( $30 \mathrm{mg} / \mathrm{kg}$ bw Fx administration), compared to those of the control mice in group 2 (Table I).

Cleaved caspase- $3^{\text {high }}$ cells are apoptosis-like cells, including anoikis-like cells. In the present study, cleaved caspase- $3^{\text {high }}$ cells were significantly increased, 1.8-fold, and in both colon adenocarcinoma and colon mucosal crypts by Fx administration in group 1 compared to those of group 2 (Figure 4A-D). This suggested that the apoptosis induction was enhanced in colonic mucosal tissue by Fx administration. On the other hand, our previous study revealed that the number of cleaved caspase- $3^{\text {high }}$ cells was remarkably elevated 3.2- and 2.7-fold in colon adenocarcinoma and colon mucosal crypts, respectively, by Fx administration during the final 3 wks before sacrifice (20). Therefore, it is suggested that the increase of apoptosis-like cells in colon mucosal tissue depended on the dosage of Fx.

Colonic TME are composed of a variety of cells, such as CCSCs, CAFs, tumor-associated macrophages, dendritic cells and immune cells, and play an essential role in cancer progression (21-23). So far, little evidence is available regarding salivary metabolite profiles associated with TME in human and animal CRC. In the present study, the number of CCSC-like CD $44^{\text {high}} / \mathrm{EpCAM}^{\text {high }}$ cells was significantly decreased, 0.7- and 0.5-fold in colon adenocarcinoma and colon mucosal crypts, respectively, by Fx administration in group 1 compared to those cells in group 2 (Figure 5A-D). These results suggest that the apoptosis induction and/or suppression of occurrence in cancer stem-like cells would be caused by Fx administration in both colon adenocarcinoma and mucosal crypts of AOM/DSS mice. In addition, the expression of CAF-like $\alpha S_{M A}{ }^{\text {high }}$ cells was decreased 0.6fold by $\mathrm{Fx}$ administration in colonic mucosal crypts of group 1 compared to those cells in group 2 (Figure 6A-D). However, no difference of CAF-like $\alpha \mathrm{SMA}^{\text {high }}$ cells was observed in adenocarcinoma between groups 1 and 2 (Figure 6A-D). We previously showed that the numbers of CD44 ${ }^{\text {high }} / \mathrm{EpCAM}^{\text {high }}$ and $\alpha \mathrm{SMA}^{\text {high }}$ cells were decreased by 0.6 - and 0.5-fold in colon mucosal crypts of AOM/DSStreated mice with Fx administration at 8 wks after the final DSS exposure compared to cells in the control mice (19). The inhibitory effects in CD $44^{\text {high }} / \mathrm{EpCAM}^{\text {high }}$ and $\alpha \mathrm{SMA}^{\text {high }}$ cells in the present study were both approximately equal to those observed in the previous study (Figures $5 \mathrm{C}$ and $\mathrm{D}, 6 \mathrm{C}$ and $\mathrm{D})$.

Several reports support our data that salivary glycine could be a good predictor of cancer prolongation. Salivary glycine in patients with breast and pancreatic cancer was significantly increased 2.32-fold and 3.10-fold against healthy controls, respectively (1). Moreover, salivary glycine in gastric cancer patients at an early clinical stage showed a 2.0-fold higher amount than that of controls (5). As the suppressive effect of Fx on TME development was also observed, we expected that salivary metabolite profiles by Fx administration would be similar to those in the previous observation (19). As expected, salivary glycine and succinic acid in group 2 increased until 11 wks, but decreased at 14 wks after the final DSS exposure (Figure 7). These two metabolites were expected to correlate with cancer progression in the mice. However, our previous study did not show significant difference in salivary succinic acid between DSS-treated mice with Fx administration and the control DSS-treated mice at 8 wks after the final DSS exposure (19). Thus, we are considering that salivary succinic acid may be a weak predictor compared to salivary glycine.

We expected that salivary glycine could be a good predictor representing cancer chemopreventive effects of Fx. Fx administration decreased salivary glycine 0.5-, 0.4- and 0.7 -fold at 4,11 and $14 \mathrm{wks}$, respectively. The rate of decrease in salivary glycine in the present study seems similar to that of the cancer chemopreventive potential of Fx. On the other hand, an increase (2.2-fold) of salivary glycine by Fx administration was observed in CCSC-like spheroid inoculated xenograft mice (24). Confirmation is needed of the alteration of salivary metabolites in various cancer animal models with Fx administration.

Saliva has an advantage for examining a physiological status of cancer patients or healthy people from the accessibility, repetition and safety $(1,5)$. Next future, the long-term effect of Fx or Fx-rich foods in cancer prevention in human may be able to explain by salivary glycine. However, the reason why salivary metabolites are changed with physiological status of both human and animals remain elusive. The clarification of 

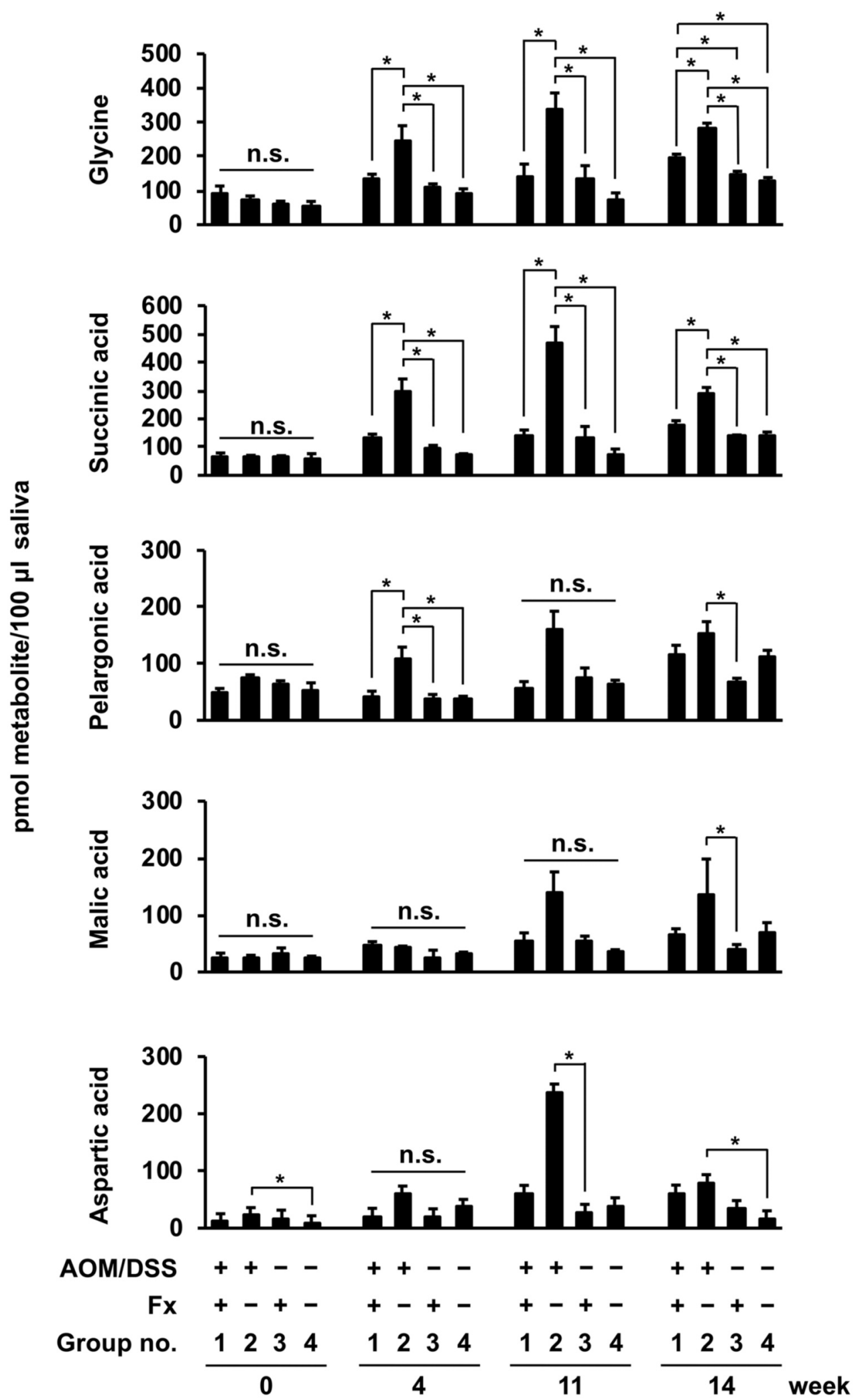

Figure 7. Salivary metabolite content in AOM/DSS mice with or without fucoxanthin (Fx). Mouse saliva was collected sequentially at 0, 4, 11, and 14 weeks after the final DSS exposure, and low molecular metabolites were analyzed by GC-MS. Mean $\pm S E(n=5)$. * $p<0.05$ and no significance (n.s.) by one-way ANOVA with post-hoc Tukey-Kramer test. 
exact mechanisms altering salivary metabolite contents must be overcome for translational research.

Taken together, our data demonstrated that Fx effectively tended to inhibit carcinogenesis in a CRC mouse model at 14 wks after the final DSS exposure along with significant alterations of apoptosis-, CCSC-, and CAF-like cells in colonic mucosal tissue. Moreover, we have successfully identified salivary glycine as an indicator for cancer chemopreventive effects of Fx in the mice during 4-14 wks after the final DSS exposure. Further in vivo studies are needed to confirm the clinical utility of salivary glycine in various carcinogenic animal models with several concentrations of Fx and with Fxrich foods.

\section{Conflicts of Interest}

The Authors declare no competing financial interest.

\section{Authors' Contributions}

Masaru Terasaki conceived and designed the study and wrote the manuscript. Masaru Terasaki, Ryota Kimura, and Takuji Tanaka performed the experiments. Atsuhito Kubota, Hiroyuki Kojima, Hayato Maeda, Kazuo Miyashita, and Michihiro Mutoh reviewed and edited the manuscript. All Authors read and approved the manuscript and agree to be accountable for all aspects of the research and ensuring that the accuracy or integrity of any part of the work is appropriately investigated and resolved.

\section{Acknowledgements}

This work was supported in part by JSPS KAKENHI Grant Number 16K07880.

\section{References}

1 Sugimoto M, Wong DT, Hirayama A, Soga T and Tomita M: Capillary electrophoresis mass spectrometry-based saliva metabolomics identified oral, breast and pancreatic cancerspecific profiles. Metabolomics 6(1): 78-95, 2010. PMID: 20300169. DOI: 10.1007/s11306-009-0178-y

2 Ishikawa S, Sugimoto M, Kitabatake K, Sugano A, Nakamura M, Kaneko M, Ota S, Hiwatari K, Enomoto A, Soga T, Tomita $\mathrm{M}$ and Lino $\mathrm{M}$ : Identification of salivary metabolomics biomarkers for oral cancer screening. Sci Rep 6: 31520-31526, 2016. PMID: 27539254. DOI: 10.1038/srep31520

3 Wang Q, Gao P, Cheng F, Wang X and Duan Y: Measurement of salivary metabolite biomarkers for early monitoring of oral cancer with ultra performance liquid chromatography-mass spectrometry. Talanta 119: 299-305, 2004. PMID: 24401418. DOI: $10.1016 /$ j.talanta.2013.11.008

4 Wei J, Xie G, Zhou Z, Shi P, Qiu Y, Zheng X, Chen T, Su M, Zhao A and Jia W: Salivary metabolite signatures of oral cancer and leukoplakia. Int J Cancer 129(9): 2207-2217, 2011. PMID: 21190195. DOI: $10.1002 /$ ijc. 25881

5 Chen Y, Cheng S, Zhang A, Song J, Chang J, Wang K, Zhang Y, Liu H, Alfranca G, Aslam MA, Chu B, Wang C, Pan F, Ma L, de la Fuente JM, Ni J and Cui D: Salivary analysis based on surface enhanced Raman scattering sensors distinguishes early and advanced gastric cancer patients from healthy persons. J Biomed Nanotechnol 14(10): 1773-1784, 2018. PMID: 30041723. DOI: $10.1166 /$ jbn.2018.2621

6 Yoshie T, Nishiumi S, Izumi Y, Sakai A, Inoue J, Azuma T and Yoshida M: Regulation of the metabolite profile by an APC gene mutation in colorectal cancer. Cancer Sci 103(6): 1010-1021, 2012. PMID: 22380946. DOI: 10.1111/j.1349-7006.2012.02262.x

7 Dazard JE, Sandlers Y, Doerner SK, Berger NA and Brunengraber $\mathrm{H}$ : Metabolomics of $\mathrm{Apc}^{\mathrm{Min} /+}$ mice genetically susceptible to intestinal cancer. BMC Syst Biol 8: 72-92, 2014. PMID: 24954394. DOI: 10.1186/1752-0509-8-72

8 Qin XY, Tatsukawa H, Hitomi K, Shirakami Y, Ishibashi N, Shimizu M, Moriwaki H and Kojima S: Metabolome analyses uncovered a novel inhibitory effect of acyclic retinoid on aberrant lipogenesis in a mouse diethylnitrosamine-induced hepatic tumorigenesis model. Cancer Prev Res 9(3): 205-214, 2016. PMID: 26744170. DOI: 10.1158/1940-6207.CAPR-15-0326

9 Terasaki M, Kuramitsu Y, Kojoma M, Kim SY, Tanaka T, Maeda H, Miyashita K, Kawagoe C, Kohno S and Mutoh M: High fucoxanthin wakame (Undaria pinnatifida) prevents tumor microenvironment formation in an AOM/DSS mouse carcinogenic model. J Func Foods 64: 103709, 2020. DOI: 10.1016/j.jff.2019.103709

10 Terasaki M, Hirose A, Narayan B, Baba Y, Kawagoe C, Yasui H, Saga N, Hosokawa M and Miyashita K: Evaluation of recoverable functional lipid components of several brown seaweeds (Phaeophyta) from Japan with special reference to fucoxanthin and fucosterol contents. J Phycol 45(4): 974-980, 2009. PMID: 27034228. DOI: 10.1111/j.1529-8817.2009.00706.x

11 Nishino H, Murakoshi M, Tokuda H and Satomi Y: Cancer prevention by carotenoids. Arch Biochem Biophys 483: 165-168, 2009. PMID: 18848517. DOI: 10.1016/j.abb.2008.09.011

12 Satomi Y: Antitumor and cancer - preventative function of fucoxanthin: a marine carotenoid. Anticancer Res 37(4): 15571562, 2017. PMID: 28373414. DOI: 10.21873/anticancers.11484

13 Shiratori K, Ohgami K, Ilieva I, Jin XH, Koyama Y, Miyashita $\mathrm{K}$, Yoshida K, Kase S and Ohno S: Effects of fucoxanthin on lipopolysaccharide-induced inflammation in vitro and in vivo. Exp Eye Res 81(4): 422-428, 2005. PMID: 15950219. DOI: 10.1016/j.exer.2005.03.002

14 Hitoe S and Shimoda H: Seaweed fucoxanthin supplementation improves obesity parameters in mild obese Japanese subjects. Func Foods Health Disease 7(4): 246-262, 2017. DOI: 10.31989/ ffhd.v7i4.333

15 Mikami N, Hosokawa M, Miyashita K, Sohma H, Ito YM and Kokai Y: Reduction of HbA1c levels by fucoxanthin-enriched akamoku oil possibly involves the thrifty allele of uncoupling protein 1 (UCP1): a randomised controlled trial in normalweight and obese Japanese adults. J Nutr Sci 6: e5, 2017. PMID: 28620480. DOI: $10.1017 /$ jns.2017.1

16 Asai A, Yonekura L and Nagao A: Low bioavailability of dietary epoxyxanthophylls in humans. Br J Nutr 100(2): 273-277, 2008. PMID: 18186952. DOI: 10.1017/S0007114507895468

17 Hashimoto T, Ozaki Y, Mizuno M, Yoshida M, Nishitani Y, Azuma $\mathrm{T}$, Komoto A, Maoka $\mathrm{T}$, Tanino $\mathrm{Y}$ and Kanazawa $\mathrm{K}$ : Pharmacokinetics of fucoxanthinol in human plasma after the oral administration of kombu extract. Br J Nutr 107(11): 1566-1569, 2012. PMID: 21920061. DOI: 10.1017/S0007114511004879 
18 Yonekura L, Kobayashi M, Terasaki M and Nagao A: Ketocarotenoids are the major metabolites of dietary lutein and fucoxanthin in mouse tissues. J Nutr 140(10): 1824-1831, 2010. PMID: 20739451. DOI: 10.3945/jn.110.126466

19 Terasaki M, Masaka S, Fukada C, Houzaki M, Endo T, Tanaka T, Maeda H, Miyashita K and Mutoh M: Salivary glycine is a significant predictor for the attenuation of polyp and tumor microenvironment formation by fucoxanthin in AOM/DSS mice. In Vivo 33(2): 365-374, 2019. PMID: 30804114. DOI: 10.21873/ invivo. 11483

20 Terasaki M, Ikuta M, Kojima H, Tanaka T, Maeda H, Miyashita $\mathrm{K}$ and Mutoh M: Dietary fucoxanthin induces anoikis in colorectal adenocarcinoma by suppressing integrin signaling in a murine colorectal cancer model. J Clin Med 9(1): 90-104, 2020. PMID: 31905803. DOI: 10.3390/jcm 9010090

21 Dalerba P, Dylla SJ, Park IK, Liu R, Wang X, Cho RW, Hoey T, Gurney A, Huang EH, Simeone DM, Shelton AA, Parmiani G, Castelli $\mathrm{C}$ and Clarke MF: Phenotypic characterization of human colorectal cancer stem cells. Proc Natl Acad Sci 104(24): 1015810163, 2007. PMID: 17548814. DOI: 10.1073/pnas.0703478104
22 Medema JP and Vermeulen L: Microenvironmental regulation of stem cells in intestinal homeostasis and cancer. Nature 474(7351): 318-326, 2011. PMID: 216777488. DOI: 10.1038/ nature 10212

23 Legitimo A, Consolini R, Failli A, Orsini G and Spisni R: Dendritic cell defects in the colorectal cancer. Hum Vaccin Immunother 10(11): 3224-3235, 2014. PMID: 25483675. DOI: 10.4161/hv.29857

24 Terasaki M, Matsumoto N, Hashimoto R, Endo T, Maeda H, Hamada J, Osada K, Miyashita K and Mutoh M: Fucoxanthin administration delays occurrence of tumors in xenograft mice by colonospheres, with an anti-tumor predictor of glycine. J Clin Nutr Biochem 64(1): 52-58, 2019. PMID: 30705512. DOI: $10.3164 /$ jcbn. $18-45$
Received July 23, 2020

Revised August 29, 2020

Accepted August 31, 2020 